\title{
Multifunctional crust breaker for automatic alumina feeding system of aluminum reduction cell
}

\author{
A.K. Shestakov ${ }^{1}$, R.M. Sadykov ${ }^{1}$, P.A. Petrov ${ }^{2}$ \\ ${ }^{1}$ Department of Technological Process Automation and Production, Saint Petersburg Mining \\ University, Saint Petersburg, Russia \\ ${ }^{2}$ Dean of the Faculty of Mineral Raw Material Processing, Saint Petersburg Mining University, Saint \\ Petersburg, Russia
}

\begin{abstract}
For efficient operation of high-power aluminum reduction cells with prebaked anodes,full-time monitoring of the main technological parameters is required.This article discusses a multifunctional crust breaker of the automatic alumina feeding system. It provides the alumina supply to the bath by breaking the continuously solidifying crust on the surface of the melt. The multifunctional crust breaker is also a part of the automatic alumina feed system, providing regular automatic measurements of the process parameters. This article describes the development of a laboratory bench with a multifunctional crust breaking device. The goal and objectives are set. The design of the device is presented in the paper. The paper shows the advantages of using an automatic alumina feeding system with the developed multifunctional crust breaker.The positive effect of using the bench in the training process is discussed.
\end{abstract}

\section{Introduction}

The aluminum industry, like any other industry, requires new solutions in the production processesto reduce the cost of the primary aluminum production. These new solutions are becoming even more relevant because of the instability of the world economy. Automation of production processes is one of the priority directions of development in any industry.

The current level of automated control of primary aluminum production does not provide timely adjustments to the technological parameters of the electrolytic aluminum reduction process, such as temperature, cryolite ratio, bath, and metal level [1,2]. Automatic process control has significant inertia due to a large number of manual operations and long intervals between measurements of process parameters [2,3].

Timely acquisition of the process data will increase the effectiveness of the control of the aluminum reduction process. It will allow to make all the necessary adjustments exactly in the time when they are needed [4-6]. 
The modernization of the monitoring system will improve the control of the process, which in its turn will increase technical and economic indicators. Therefore, the task of creating an automatic parameter control system is important for the aluminum industry.

\section{Automatic alumina feeding system}

An automatic alumina feeding system is installed on a high-power aluminum reduction cell. It provides a discrete input of alumina into the bath in small portions, sufficient until the next feeding cycle without the appearance of aluminum oxide deposited at the bottom of the cell. Conditions near each feeder holes are different, for example, the rate of the melt, the concentration of alumina, and the cryolite ratio $[3,4]$.

The task of the automatic alumina feeding system is to maintain the concentration of alumina in the melt at a certain level at all feeding points of the bath. There are two ways to fulfill this task:

1) to maintain the power frequency characteristic of the potlines

2) to use algorithms to estimate the current concentration.

The potential for increasing current efficiency and reducing specific power consumption should be realized by improving algorithms for alumina feeding [2]. These algorithms should be based on automatically measured process parameters at specific points in the bath. Thus, the automatic system will generate an individual control signal for the feeding point.

\section{Multifunctional crust breaker as a part of the automatic data acquisition system}

Along with the problem of the absence of an automated control system for the main technological parameters of the alumina reduction process (determination of the bath temperature, cryolite ratio, metal and bath levels), there is a problem of crust forming on the surface of the melt in the feeder hole (Figure 1) [7-9].

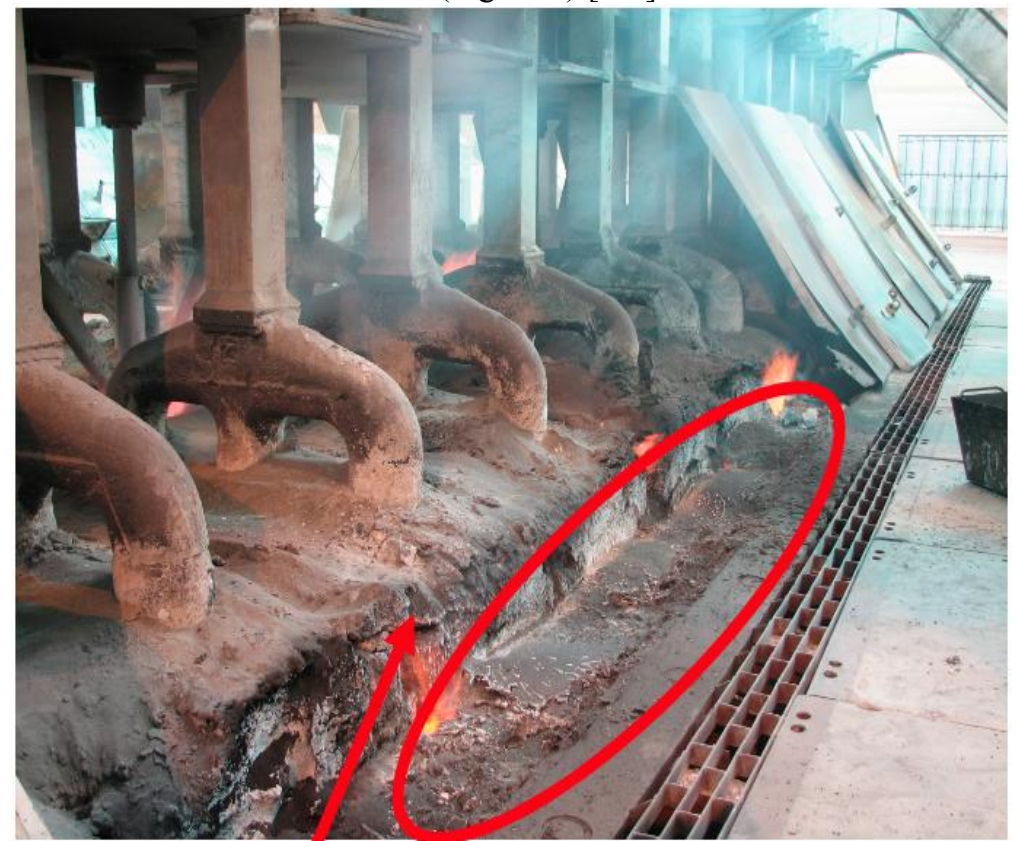

Fig. 1. The crust of cryolite melt. 
The crust is located on the surface of the cryolite and covers it. On the one hand, the crust keeps heat in the bath and reduces energy losses. On the other hand, continuously forming crust interrupts the regular supply of alumina feed to the electrolyte. In order to provide the alumina supply to the bath, crust breakers are used [10-12]. Automated crust breakers are part of the automatic alumina feed system. If the crust is not broken, and the monitoring is not carried out, the continuation of the alumina supply will lead to the accumulation of alumina on the surface of the crust (Figure 2) $[13,14]$.
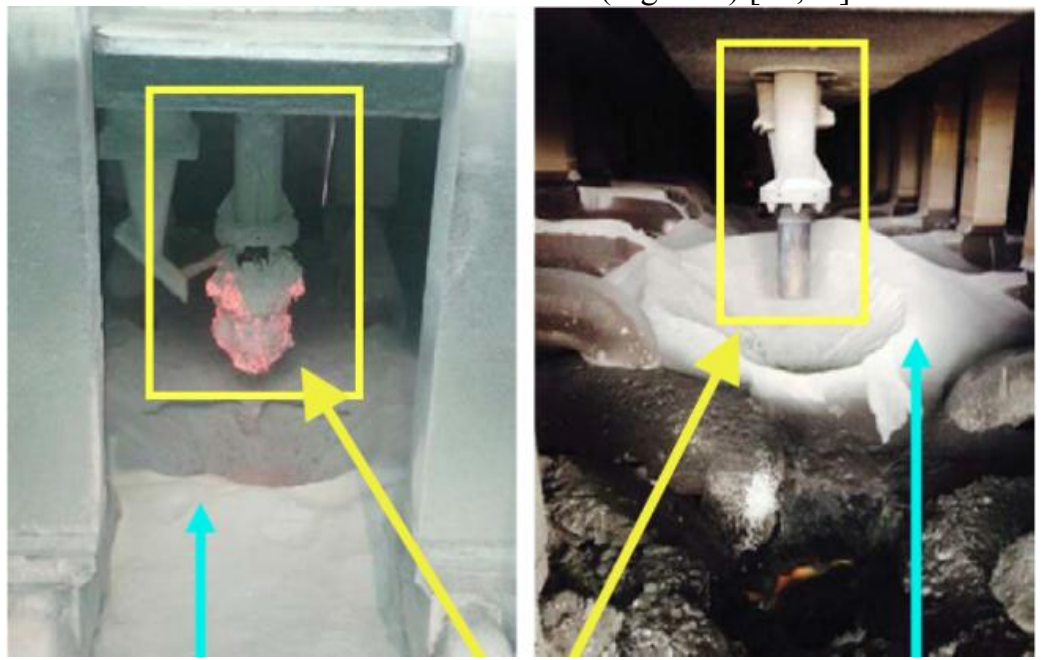

Fig. 2. Accumulation of alumina near feeding points.

The existing problems, such as a lack of an automatized acquisition of technological parameters of the electrolysis process and lack of control the process of breaking the crust could be solved by the development of a multifunctional crust breaker for an automatic alumina feeding system of aluminum reduction cell.

The purpose of developing a multifunctional crust breaker is to increase the efficiency of aluminum production process control during its reduction by developing and applying technical solutions for continuous automatic monitoring of technological parameters of the electrolysis process under aggressive conditions of primary aluminum production, such as high temperature and strong magnetic fields [3].

For this purpose, it is necessary to modernize the existing automatic alumina feeding system.

The advanced automatic alumina feeding system should perform the following tasks:

1) Monitor the process of breaking the crust in the feeder hole

2) Measure the bath level

3) Measure the metal level

4) Measure the temperature of the bath

5) Measure the bath resistance and determining the cryolite ratio (CR)

6) Adjust the alumina feed rate depending on the $C R$ value and maintain $C R$ in the required range $(2.2-2.4)$.

The idea of the work is to use a crust breaker to measure the resistance of the bath that changes with the change of the immersion depth of the chisel. Resistance tracking allows to monitor the process of breaking through the crust (adding feedback to the system) and measure (monitor) the levels of the bath and molten aluminum.

The short immersion time of the crust breaker allows it to be used not only as a device for breaking the crust, but also as a mobile platform for sensors, thus avoiding a prolonged stay in an aggressive environment, and provide regular automatic measurements of the 
process parameters. In this regard, it can be considered as a multifunctional device (Figure 3).

In the measurement circuit, an electrode is mounted to the chisel of the crust breaker, the second electrode is mounted to the cathode located at the bottom of the electrolysis bath. The moment of breaking the crust is registeredby the contact of the chisel of the crust breaker with the bath and contact with the surface of molten aluminum (deposited on the cathode at the bottom of the electrolysis bath), the resistance, as well as the current of the resulting electrical circuit, will be different.To measure the depth of immersion of the crust breaker, the chisel requires the use of a position sensor mounted on the pneumatic cylinder. The position of the rod is measured by a sensor using a magnetic ring mounted inside the piston of the pneumatic cylinder.

In order to detect the touch between the surface of the bath and the surface of the metal, an electrode must be installed on the crust breaker. The other electrode must be installed in the cell itself. These electrodes must be supplied with a voltage of $24 \mathrm{~V}$ [4]. When the chisel is lowering into the electrolyte, the distance between the electrodes and the electrical resistance is changing. The crust breaker itself must be isolated. That kind of isolated design is required in order to ensure that the measurement of electrical parameters will not be affected by a drop in the voltage in the potline.

It is suggested to use two modes of operation of the device, i.e., at high and low pressure. The utilization of these two modes reduces air consumption. The low-pressure mode is used by default for the direct stroke of the rod. If the pressure in normal mode was not enough to break the crust, then the second attempt in high-pressure mode will be used to break the crust. The process is controlled by a PLC that monitors the breaking status. The reverse stroke of the piston is performed only at high pressure.

It is assumed to use a low-inertia thermal sensor (chromel-alumel thermocouple) to measure the temperature of the electrolyte. It should be installed inside the chisel of the crust breaker and be connected with an armored, heat-resistant cable.

Thus, the developed system provides an automatic acquisition of the main parameters of the cryolite-alumina melt electrolysis process: the temperature of the electrolyte, the levels of the electrolyte and the metal, as well as to indirectly calculate the CR [15].

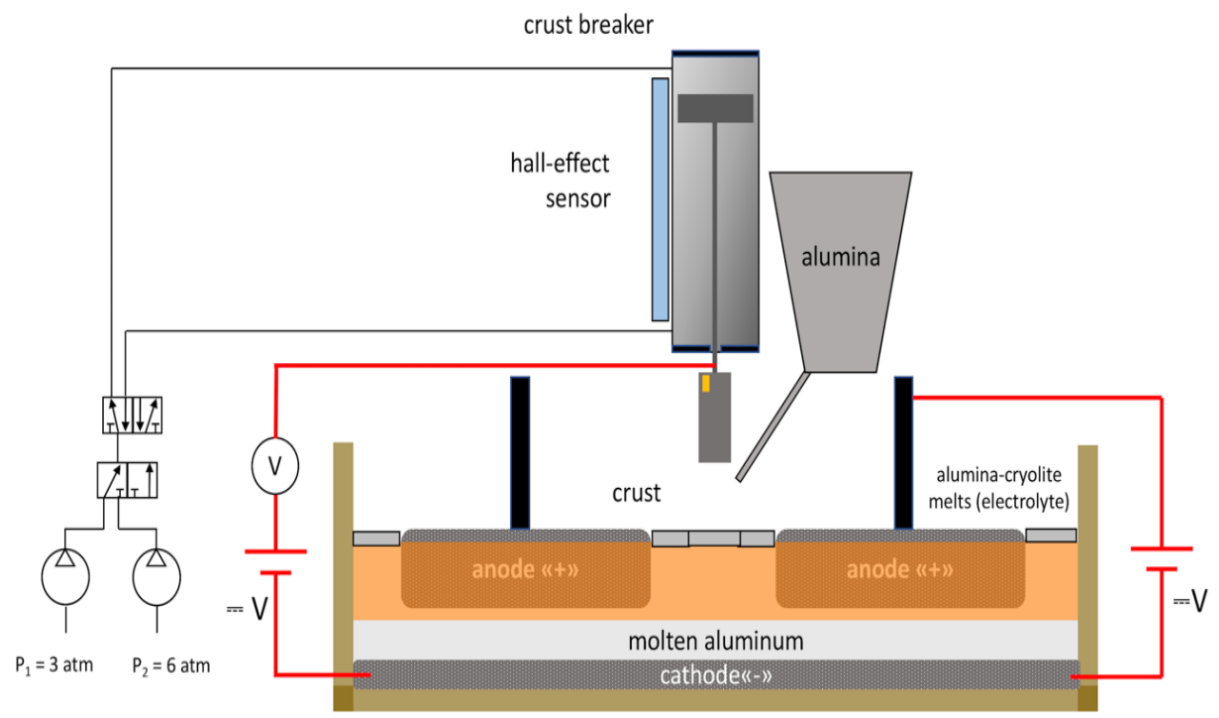

Fig. 3. A scheme of the multifunctional crust breaking device. 
CR could be found with the following equation:

where $\mathrm{N}$ is the frequency calibration coefficient

$$
C R=N \cdot R_{m} \cdot \frac{S}{l_{m}}=\frac{U \cdot S}{l_{m} \cdot I_{m}},
$$

$\mathrm{R}_{\mathrm{m}}$ is the calculated electrical resistance of the measured electrolyte layer

$\mathrm{U}$ is the voltage, $24 \mathrm{~V}$

$\mathrm{S}$ is the contact area of the crust breaker with the melt

$1_{\mathrm{m}}$ is the measured bath level

$\mathrm{I}_{\mathrm{m}}$ is the measured current.

Measurement of the current $\mathrm{I}_{\mathrm{m}}$ is made when the chisel of the probe touches the bath.

In addition to the theoretical study of the problem, practical work is being carried out. Alaboratory bench "Multifunctional crust breaker for automatic alumina feeding system of aluminum reduction cell"is being developed at the Department of Automation of Technological Processes and Productions of Saint Petersburg Mining University (Figure 4).

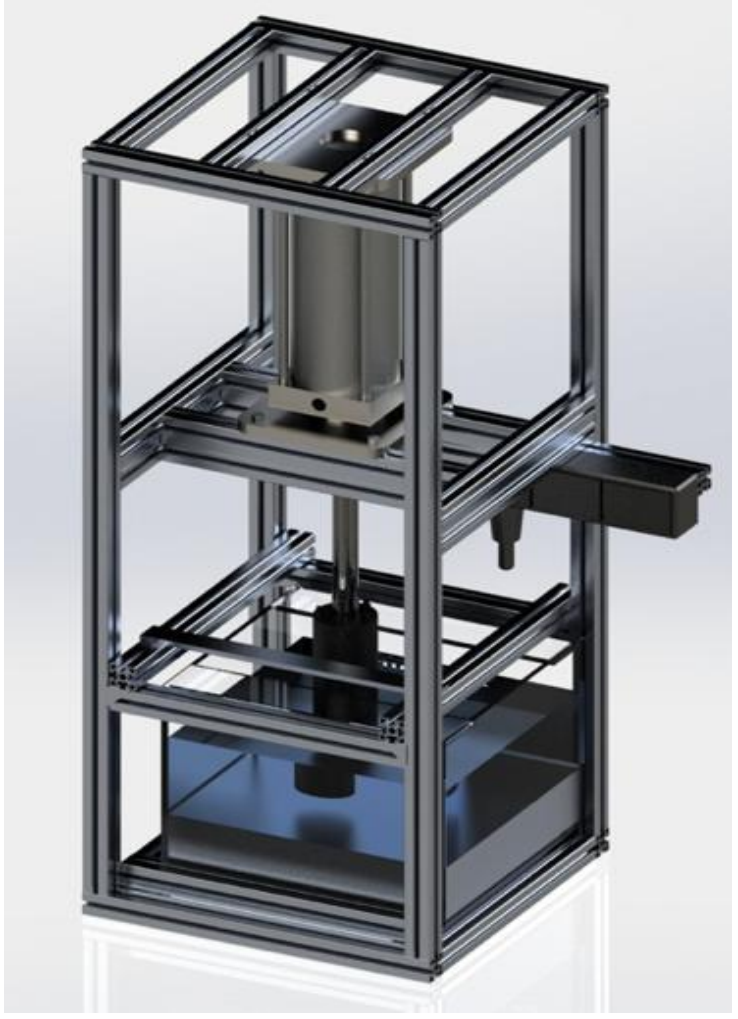

Fig. 4. A 3D model of the bench "Multifunctional crust breaker for automatic alumina feeding system of aluminum reduction cell".

The demonstration bench simulates the operation of the device for breaking the crust. The control the process of breaking the crust is monitored. The role of the crust is performed by foam. The levels of the electrolyte and metal are determined (water and a liquid with a lower density and a different resistance from water are used). A thermocouple is "sealed" in the chisel of the crust breaker. 


\section{Similar devices}

\subsection{Description of the Smart Touchsystem}

A similar Smart Touch device (patent RU 2425180 "Method of controlling an aluminum reduction cell") was developed by Camozzi in cooperation with RUSAL.

In this device, a pulse generator is connected to the body of the pneumatic cylinder and to the anode of the aluminum reduction cell. The frequency of the generated pulses is based on the parameters of the frequency-setting circuit, such as the bandpass filter, the capacity of the pneumatic cylinder body relative to the anode, the capacity of the pneumatic cylinder body relative to the piston and rod, and the variable capacity of the gap between the chisel and the bath surface.

The chisel-anode system behaves like a capacitor due to the use of alternating current when the contact is open.

In the initial position of the crust breaker, the capacity between the crust breaker and the bath surface is small because the gap is large. The frequency of the controlled pulse generator ranges from 10 to $30 \mathrm{kHz}$.

When the crust breaker touches the bath surface, the pulse frequency of the controlled generator decreases by more than $20 \%$ of the initial value. At this point, the automatic system sends a signal to return the crust breaker to its original state. So, the chisel stays in the electrolyte (in the melt) for the minimalamount of time $(0.25 \mathrm{~s})$. Such a system prevents the electrolyte from sticking to the chisel, reduces the number of accidents when the chisel cannot break through the crust. In this scenario, the supply of alumina is blocked, which leads to anode effects (AE). Also, the service life of the chisel increases and the wear of the chisel decreases.

The disadvantage of the Camozzi system in comparison with the developed system is the lack of a system for determining the position of the pneumatic cylinder rod, as well as the lack of a built-in thermocouple in the body of the crust breaker devices.

\subsection{Comparison of the chisel service life of different crust breaker devices}

The service life before replacing the steel chisel of the crust breaker in a traditional automatic power supply system (without the control of the process of breaking the crust) is 12 months.Replacement of the chisel is required due to mechanical and corrosion effects. In a system without crust breaker control, the chisel is immersed in the electrolyte at half its height for $0.6 \mathrm{~s}$ (data obtained from production experience). At the same time, according to the power supply algorithms, a new portion of alumina enters the electrolyte 1 time per minute. Thus, for 12 months, the chisel of the crust breaker is in contact with the electrolyte for

$$
0.6 \cdot 60 \cdot 24 \cdot 365 \div 3600=87.6 \mathrm{~h} / \text { year }
$$

Based on laboratory tests, it is known that in the Smart Touch system of Camozzi, during the operation of breaking through, the chisel of the crust breaker touches with the lower part of its surface the electrolyte for $0.25 \mathrm{~s}$. As alumina is supplied 1 time per minute, we receive

$$
0.25 \cdot 60 \cdot 24 \cdot 365 \div 3600=36.5 \mathrm{~h} / \text { year } .
$$

In the developed Multifunctional Crust Breakdown Device system, power is suppliedonce a minute; in addition, every hour, the electrolyte and metal levels are measured, and the temperature is automatically measuredtoo (this operation takes 20 seconds). 
Based on laboratory tests, it is known that during the operation of breaking through, the chisel of the crust breaker touches the electrolyte with the lower part of its surface for 0.25 $\mathrm{s}$. Thus, the total duration is

$$
(0.25 \cdot 60 \cdot 24+20 \cdot 24) \cdot 365 \div 3600=85.17 \mathrm{~h} / \text { year }
$$

Based on the calculations, we can conclude that the proposed Multifunctional Crust Breakdown Device systemdoes not reduce the service life of the crust breaker chisel. The service life of the crust breaker chisel in the proposed system is 12 months (as in the traditional system). A similar Smart Touch system from Camozzi increases the service life of the crust breaker chisel by 2 times, butthis system does not control the levels of electrolyte and metal, it also does not measure the temperature of the electrolyte.

\section{Simulation modeling of chisel heating of the crust breaker device}

At this moment, the temperature of the cryolite-alumina melt in aluminum reduction cell with prebaked anodes is measured twice a week manually by dipping a thermocouple through a hole in the crust. In order to do that, it is necessary to open the side doors of the aluminum reduction cell, that is, to depressurize it and disrupt the operation of the dry gas cleaning system, which leads to the release of harmful perfluorocarbons (PFCs) into the environment and negatively affects the health of the staff. In addition, measuring the temperature of the electrolyte two times a week is insufficient at the established rate to reduce the number of $\mathrm{AE}$.

Installing a thermocouple in the lining of an electrolysis bath requires stopping the operation of the bath for a long period of time for installation work, which directly leads to economic losses.

The dustiness is a factor that prevents an implementation of non-contact methods for measuring temperature, for instance, to use pyrometers.

In this paper, we propose a method for automatic temperature measurement by placing a thermocouple inside the chisel of the crust breaker. The chisel has a shape of a cylinder and made of stainless steel. It is proposed to install one thermocouple per cell. To do this, it is necessary to make a non-through vertical technical hole with a diameter of $4 \mathrm{~mm}$ in the upper part of the cylinder for installing the thermocouple. In the ANSYS software package, the module for solving dynamic problems of temperature field distribution (transient thermal) simulates the temperature distribution over time along the chisel of the crust breaker when immersed in a cryolite-alumina melt. As a result of simulation, it was found that after $200 \mathrm{~s}$ the cylinder warms up to the electrolyte temperature $\left(950^{\circ} \mathrm{C}\right)$ for a thickness of $4 \mathrm{~mm}$ (Figure 5). Therefore, the technical hole is proposed to be made at distance of 4 $\mathrm{mm}$ from the cylinder wall. Since the measurement inertia of the thermocouple, according to the documentation, is $1 \mathrm{~s}$, therefore, to measure the temperature of the cryolite-alumina melt, it is necessary that the chisel of the crust breaker is in contact with the measured medium for at least $200 \mathrm{~s} 1$ time per hour. It is required to submerge the chisel of the crust breaker to a depth of $2 / 3$ of the height of the cylinder. 


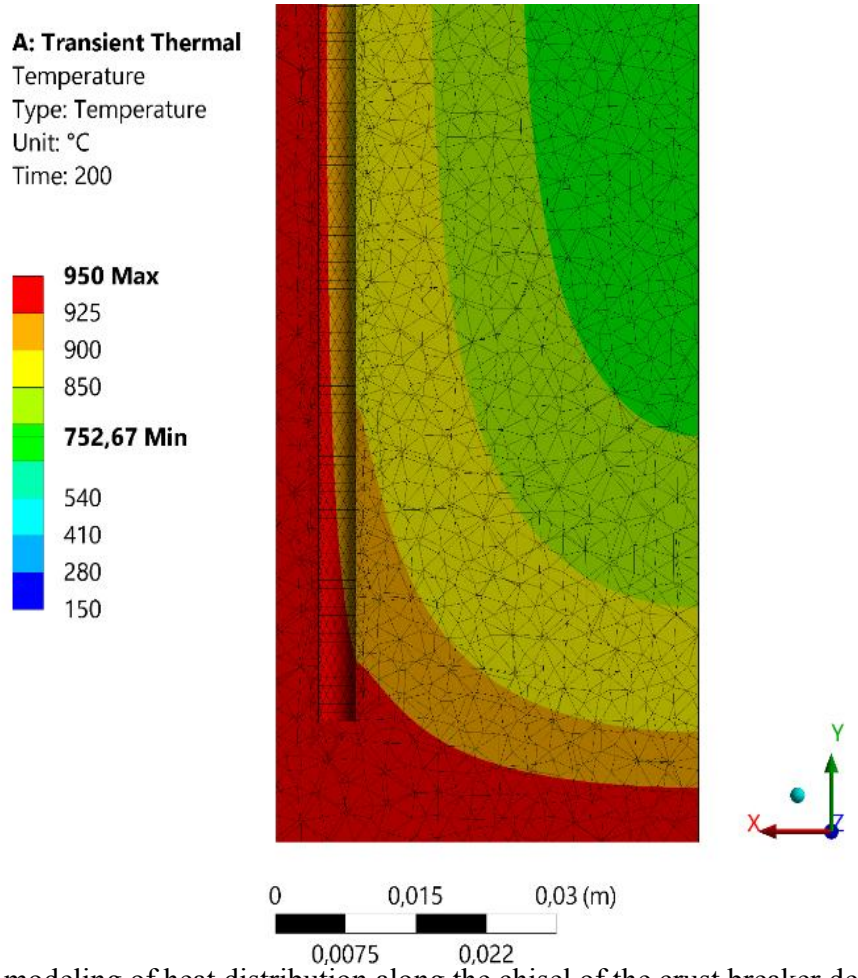

Fig. 5. Results of modeling of heat distribution along the chisel of the crust breaker device.

The thermocouple located in the chisel of the crust breaker, including the cold junction, must be completely in a ceramic case, i.e. in an electrically insulated material capable of conducting heat.

The proposed method is characterized by low costs for the modernization of the automatic alumina feeding system. Moreover, the crust breaker and its chisel can be dismantled during the operation of the reduction cell, without performing costly work on its stop and restart.

\section{Expected effects of implantation of a multifunctional crust breaker device}

\subsection{Economic effects}

According to the results of the production experience of the Boguchansky aluminum smelter, the use of the developed system allows to increase the current efficiency by $0.7 \%$. The current efficiency is increased by the use of an automatic system for measuring the levels of electrolyte and liquid metal in the reduction cell, as well as by using an automatic system for measuring the temperature of the electrolyte. This makes it possible to maintain the minimum permissible value of anode-to-cathode distance (ACD) more accurately, without allowing local overheating of the electrolyte.

Increasing the current efficiency by $0.7 \%$ will result in increased performance:

$$
P=k \cdot I \cdot \eta \cdot \tau
$$

where I is the current strength, $\kappa \mathrm{A}$; $\tau$ is the amount of time ( $8760 \mathrm{~h} /$ year).

For a single reduction cell: 


$$
P=0.3356 \cdot 320 \cdot 0.007 \cdot 8760=6585.28 \frac{\mathrm{kg}}{y e a r} .
$$

For a smelter with 792 cells:

$$
P=792 \cdot 6585.28=5215541.76 \frac{\mathrm{kg}}{\text { year }} .
$$

or 5.215 thousand $\mathrm{t} /$ year.

Additional revenue from increased production:

$$
P=2028 \cdot 5215541.76=\$ 10577 \text { million year }
$$

where 2028 is thethe price of one ton of aluminum on the London metal exchange as of 20.12.2020 in USD.

The cost of implementing a multifunctional crust breaker device is presented in Table 1 (data provided for the aluminum smelter).

\begin{tabular}{|c|c|c|c|}
\hline \multicolumn{4}{|c|}{ Equipment cost: } \\
\hline on 1 reduction cell, USD & 7548 & 10777 & 3229 \\
\hline on entire smelter, USD & 5980630 & 8545534 & 2564904 \\
\hline \multicolumn{4}{|c|}{ Introduction of } \\
\hline new technology costs, US & & 0000 & 2240000 \\
\hline Total, USD & 5980630 & 10785534 & 4804904 \\
\hline
\end{tabular}

Table 1. The cost of implementing the multifunctional crust breaker device.

\begin{tabular}{lll}
\hline Cost item & Other systems $\quad$ Developed system Difference \\
\hline
\end{tabular}

The results of calculations showed that the developed Multifunctional Crust Breaker Device systemis cost-effective and the payback period will be less than 13 months.

This unit operates at a reduced pressure of $3 \mathrm{~atm}$ instead of the high pressure in the compressed air supply network. As a rule, if there is a hole in the electrolyte crust, little pressure is needed to drive the cylinder. This saves the compressed air.

The compressed air flow rate for a cylinder with a piston diameter of $200 \mathrm{~mm}$, a rod diameter of $40 \mathrm{~mm}$, and with a stroke of $400 \mathrm{~mm}$, operating at a high pressure of 6 atm (the process of breaking the crust occurs once a minute) is calculated by Equation 9 (Bazhin et al. 2010):

$$
Q=\frac{\left(P_{S}+1\right)}{1000 \cdot P_{0}} \cdot S \cdot(A 1+A 2) \cdot n
$$

where $\mathrm{P}_{\mathrm{s}}$ is the supply pressure (atm); $\mathrm{P}_{\mathrm{o}}$ is the atmospheric pressure (atm); $\mathrm{A} 1$ is the piston area $\left(\mathrm{cm}^{2}\right)$; A2 is the piston area of the rod cavity $\left(\mathrm{cm}^{2}\right) ; \mathrm{s}$ is the piston stroke $(\mathrm{cm}) ; \mathrm{n}$ is the number of cycles per minute (cycle/min); Q is the compressed air flow rate (normal) ( $1 / \mathrm{min})$. In this case, the compressed air consumption will amount to

$$
Q=\frac{(6+1)}{1000 \cdot 1} \cdot 40 \cdot(314+301,5) \cdot 1=172.34 \mathrm{l} / \mathrm{min},
$$


The compressed air flow rate for the same cylinder using the Multifunctional Crust Breaker Device operating at a reduced pressure of 3 bar and the return from the electrolyte level, reduces the stroke by $50 \mathrm{~mm}$ is calculated by Equation 11:

$$
Q=\frac{(3+1)}{1000 \cdot 1} \cdot 35 \cdot(314+301,5) \cdot 1=86.34 \mathrm{l} / \mathrm{min}
$$

Thus, the use of a multifunctional crust breaker device leads to a $50 \%$ saving of compressed air.

At reduced pressure, the wear of the cylinder seals decreases, and its service life increases. This results in lower maintenance costs for the crust breakers.

\subsection{Other (positive) effects of the implementation of the multifunctional crust breaker}

Returning of the chisel from the bath level provides several advantages. Since the chisel of the crust breaker is not immersed in the electrolyte, itis less heated, reducing the likelihood of sticking to the electrolyte. It also reduces the chance of blocking the supply of alumina to the electrolyte and the occurrence of anode effects. The service life of the crust breaker device increases and, as a result, its maintenance costs are reduced. The quality of the aluminum is improved since it does not receive steel impurities from the chisel of the crust breaker device.

An important aspect of the concept of effective control of a powerful aluminum electrolyzer is the organization of work without anode effects. The advantages of the system can deal with anode effects and reduce their coefficient to 0.03 . For example, due to the low consumption of compressed air, all cylinders can be produced simultaneously if it is necessary to extinguish the increasing voltage that causes the anode effect. Also, the low consumption of compressed air allows to supply alumina to the aluminum reduction cell more often and in small portions. This makes it possible to achieve greater stability of the concentration of alumina dissolved in the electrolyte.

\section{Conclusions}

For a long period, the crust breakers were not presented in the design of the aluminum reduction cell. The breaking crust operation fulfilled for feeding alumina was carried out manually. Only over time, the intensive and hard labor procedure was automated, making this operation part of the automatic system.

Implementation of a multifunctional crust breaker device will allow automatically monitor the crust breaking process and measure technological parametersof the process. The use of the device will also allow to feed alumina to the electrolysis baths without precipitation on the bottom of the cell while alumina feed rate is close to the theoretical maximum. Implementation of this device will also allow to modernize existing and develop new control systems for the electrolytic aluminum reduction process.

Implementation of the multifunctional crust breaker for automatic alumina feeding system of aluminum reduction cell will bring the following benefits:

Automatic control of the crust breaking process and technological parameters of the aluminum reduction process

Provision ofcontinuous transmission of technological state information of the process simultaneously with the alumina feed of the high-temperature unit

- Maintainingthe alumina feed supply to the baths without alumina deposition on the bottom of the pot 
- Modernization ofexisting and development of new control systems for the process of electrolytic aluminum production

- $\quad$ Energy saving energy and increased lifetime of the pneumatic system by using a low-pressure mode

- Reducing the number of openingsin the enclosed space of the aluminum reduction cell

- $\quad$ Reducing the presence ofpeople in the hazardous zone (during electrolysis harmful electrolyte fumes are emitted)

- $\quad$ Reducing the costs ofdirect human labor

- Improved quality, increased predictability of primary aluminum quality.

The application of the developed bench of the multifunctional crust breaker in training will allow students to study the design of the crust breaking device, understand pneumatic and electrical circuits, practice PLC programming skills, as well as learn alumina feed algorithms. The stand can be also used as a training simulator for employees of specialized enterprises to improve their skills.

This work was carried out as part of the State Assignment No. 075-00314-20-02.

\section{References}

1. A. K.Shestakov, R. M. Sadykov, P. A. Petrov State of Primary Aluminum Production at The Beginning of 2020,International Research Journals, 1,114-119 (2020).

2. P. A.Petrov, Y. V. Sharikov, A. A. Vlasov, V. Y. Bazhin, A. Y. FeoktistovDeveloping Software for the Feed-Control Systems of High-Power Aluminum Reduction Cells,Metallurgist,58, 1060-1063 (2015).

3. V. Y.Bazhin, A. V. Lupenkov, A. A. VlasovThe Management Process Higher Amperage Aluminum Cell by Automatic Feeding Systems. In:Kholkin, A. I., Polyakov, P. V. \&Makarov, V. A. (eds.) The Second International Congress NonFerrous Metals, Krasnoyarsk, Russia (2010).

4. V. Y.Bazhin, D. V. Makushin, A. V. Saitov Production Strategy of Aluminium Reduction Pot without Anode Effect,Journal of Mining Institute,202,147-150 (2013).

5. E.S. Gorlanov, V. N. Brichkin, A. A. Polyakov Electrolytic Production of Aluminium. Review. Part 1. Conventional Areas of Development. TsvetnyeMetally, 926, 36-41 (2020).

6. E.S. Gorlanov, R. Kawalla, A. A. Polyakov Electrolytic Production of Aluminium. Review. Part 2. Development Prospects. TsvetnyeMetally, 934, 42-49 (2020).

7. J.Verreault, B. Desgroseilliers, R. Gariépy, C. Simard, S. Simard, X. Delcorde, C.Turpain, S.-P. Déry, Retrofit of a Combined Breaker Feeder with a Chisel Bath Contact Detection System to Reduce Anode Effect Frequency in a Potroom. Light Metals: 467-470. (2011).

8. A. D. Smol'nikov, Y. V. Sharikov Simulation of the Aluminum Electrolysis Process in a High-Current Electrolytic Cell in Modern Software,Metallurgist, 63, 1313-1320 (2020).

9. R.Y .Feshchenko, O.O. Erokhina, A.L. Kvanin, V.V. Vasilyev, D.S. Lutskiy, Analytical Review of the Foreign Publications about the Methods of Rise of Operating Parameters of Cathode Blocks During 1995-2014. CIS Iron Steel Rev, 13, 48-52 (2017). 
10. N.V. Vasyunina, N. A. Sharypov,S. K. Zhed, I.P. Vasyunina Influence of the Granulometry of the Cryolite-Alumina Mix on Crust Formation of the Aluminum Reduction Cell. TsvetnyeMetally, 2, 45-50 (2019).

11. L. A. Isaeva, Y. G. Mikhalev, N. Y. Zharinova Dynamics of Formation and Properties of Cryolite-Aluminous Crusts. TsvetnyeMetally, 56-61 (2020).

12. O. V. Yushkova, L. A. Isaeva, P. V. Polyakov, E. G. Avvakumov The Influence of Mechanical Activation on the Dust Index and the Dissolution Rate of Alumina in the Molten Cryolite. TsvetnyeMetally, 8, 63-68 (2018).

13. A. P. Pyankin,A. V. Trifonov,A. V. Pyankina, V. G.Grigoriev, S. V. Tepikin Introduction of the Automatic System for Raw Material Supply. In:Kholkin, A. I., Polyakov, P. V. \& Makarov, V. A. (eds.), The Tenth International Congress "NonFerrous Metals and Minerals - 2018". Krasnoyarsk, Russia (2018).

14. V.G .Grigoriev, S.V. Tepikin, A.V. Yermakov, A.P .Pyankin, A. V. ZavadyakCentralized Alumina Distribution to Point Feeding System Bins of Ra-550 Cells in JSC «RusalSayanogorsk» Pilot Potroom. In:Pashkov, G. L., Polyakov, P. V. \& Makarov, V. A. (eds.), The Eighth International Congress Non-Ferrous Metals \& Minerals 2016. Krasnoyarsk, Russia (2016).

15. L.Bracamonte, K. Nilsen, C. Rosenkilde, E. Sandnes Alumina Concentration Measurements in Cryolite Melts. In: A., T., ed., Light Metals 2020, San Diego, California, USA. Springer, 600-607 (2020). 